\title{
BMJ Open Physical heaviness of work and sitting at work as predictors of mortality: a 26- year follow-up of the Helsinki Birth Cohort Study
}

\author{
Tuija M Mikkola, ${ }^{\oplus 1}$ Mikaela B von Bonsdorff, ${ }^{1,2}$ Minna K Salonen, ${ }^{1,3}$ \\ Hannu Kautiainen, ${ }^{1,4}$ Leena Ala-Mursula, ${ }^{5}$ Svetlana Solovieva, ${ }^{6}$ Eira Viikari-Juntura, ${ }^{6}$ \\ Johan G Eriksson ${ }^{1,7}$
}

To cite: Mikkola TM, von Bonsdorff MB, Salonen MK, et al. Physical heaviness of work and sitting at work as predictors of mortality: a 26year follow-up of the Helsinki Birth Cohort Study. BMJ Open 2019;9:e026280. doi:10.1136/ bmjopen-2018-026280

- Prepublication history and additional material for this paper are available online. To view these files, please visit the journal online (http://dx.doi. org/10.1136/bmjopen-2018026280).

Received 24 August 2018 Revised 21 December 2018 Accepted 8 April 2019

Check for updates

(C) Author(s) (or their employer(s)) 2019. Re-use permitted under CC BY-NC. No commercial re-use. See rights and permissions. Published by BMJ.

For numbered affiliations see end of article.

Correspondence to Dr Tuija M Mikkola; tuija.mikkola@folkhalsan.fi

\section{ABSTRACT}

Objectives To examine the relationships of late-career physical heaviness of work and sitting at work with mortality. A national-level job exposure matrix was used to determine the occupation-specific level of physical heaviness and sitting.

Design Prospective cohort study between years 1990 and 2015.

Setting Community.

Participants 5210 men and 4725 women from the Helsinki Birth Cohort Study with an occupational code at baseline (ages 45-57 years).

Primary and secondary outcome measures Total, cardiovascular (International Classification of Diseases 10th Revision I00-199), cancer (C00-C97) and external (S00-Y84) mortality.

Results The exposures, physical heaviness and sitting had a non-linear, inverse relationship. During the 26-year follow-up, 1536 men and 759 women died. Among men, physical heaviness of work was positively associated and sitting at work was negatively associated with allcause, cardiovascular and external cause mortality but they were not associated with cancer mortality. The HRs for men in the highest quartile of physical heaviness of work compared with men in the lowest quartile were 1.54 (1.31-1.80) for all-cause mortality, 1.70 (1.30-2.23) for cardiovascular mortality and 3.18 (1.75-5.78) for external cause mortality (adjusted for age and years of education). Compared with the lowest quartile, the HRs for the highest quartile of sitting at work among men were 0.71 (0.61-0.82) for all-cause mortality, 0.59 (0.45-0.77) for cardiovascular mortality and $0.38(0.22-0.66)$ for external cause mortality. In women, neither physical heaviness of work nor sitting at work was associated with mortality. Conclusions Men in physically heavy work at their late-work career are at higher risk of death than men in physically light work.

\section{INTRODUCTION}

Given the well-established link between sedentary lifestyle and poor health, ${ }^{12}$ it has been suggested that physical inactivity also at work is a risk factor for morbidity and mortality
Strengths and limitations of this study

- An important strength was the long follow-up (26 years). Long follow-up may be crucial when studying mortality in relation to non-communicable diseases, many of which develop slowly.

- The study sample included both men and women

- Different causes of death as outcomes were a strength.

- A limitation in using solely register data is that lifestyle factors could not be controlled for.

- Use of group-based estimates for the exposures (ie, job exposure matrix) may lead to non-differential misclassification errors.

and that physically demanding job would act as a protective factor against several non-communicable diseases (NCD) ${ }^{34}$ However, there is no convincing evidence that physically demanding job would be associated with reduced mortality and that sitting at work would increase the risk of mortality. ${ }^{4-20}$ Actually, high physical work demands may translate into higher morbidity and eventually mortality. In particular, long hours of heavy work may have adverse effects on the workers' cardiovascular system. ${ }^{21} 22$ Occupational physical activity increases 24 hours' heart rate, which is an independent risk factor for cardiovascular disease and mortality. ${ }^{223}$ In addition, recovery from physically demanding work is often insufficient from physiological perspective. This may lead to sustained inflammation, which further may increase the risk of cardiovascular diseases. ${ }^{22}$

Several studies have focused on the associations between physical demands at work and mortality, with inconclusive results. ${ }^{4-14}$ Some studies have shown that higher physical demands increase the risk of death ${ }^{5-8}$ while others have shown contrasting results ${ }^{4-11}$ or 
no association. ${ }^{12-14}$ Further, several studies have reported no associations between occupational sitting and mortality, ${ }^{16-20}$ although some have suggested a positive association $^{3}$ or a U-shaped association. ${ }^{4}$ There has been a great variability in the definitions of physical demands of work. Some of the prior studies have defined it by high-energy expenditure, ${ }^{11}{ }^{24}$ some by heavy work tasks, such as lifting and carrying, ${ }^{82}$ and some by combination of energy expenditure and heavy tasks. ${ }^{46}$ Different definitions and measurement methods of the exposures can affect the results obtained. However, there seems to be no clear trend that similar definitions would yield to similar associations found. The variability in the results may also be partly explained by limited statistical power. An analysis between occupational physical demands and mortality requires a large number of person-years. In addition, it may even take several decades for many NCDs, such as type 2 diabetes and cardiovascular disease, to develop. Hence, the follow-up of mortality should be sufficiently long in order to capture the deaths that emerge in older age but this has rarely been the case in previous studies.

A job exposure matrix (JEM) is a promising tool for assessing occupational exposures in large epidemiological studies, as well as in studies including job titles, but lacking information on individual exposures. ${ }^{27}$ In JEMs, the exposures within each occupation have typically been determined using expert evaluations or self-reports of the general population.

Studying long-term outcomes of potential work-related risk factors is important. Identifying risk factors and workers at risk help in modifying work tasks, processes or work environment or focusing preventive measures to improve workers' health during their work career and even beyond it. The purpose of this cohort study was to investigate whether late-career physical heaviness of work and sitting at work are associated with all-cause and cause-specific mortality in a 26-year follow-up. We used a national-level JEM to determine the occupation-specific likelihoods of the aforementioned exposures. We hypothesised that physical heaviness of work increase and prolonged sitting at work decrease the risk of all-cause and cardiovascular mortality in both men and women. Prolonged sitting was hypothesised to diminish mortality risk since occupations requiring high levels of sitting rarely include high levels of physically heavy tasks, which are assumed to be harmful.

\section{METHODS}

The present study is a prospective analysis on the associations of physical heaviness of work and sitting at work, determined in year 1990, with mortality followed up until year 2015.

\section{Participants}

The Helsinki Birth Cohort Study (HBCS) comprises 13345 individuals born at Helsinki University Central Hospital or Helsinki City Maternity Hospital between
1934 and 1944 and still alive and residing in Finland in $1971 .^{28}{ }^{29}$ Of them, 563 died and 1140 moved abroad before year 1990. Additionally, 1664 did not have any occupational code in 1990, leaving 9935 persons available for the analysis. The register data from Statistics Finland were linked to the participants using a unique personal identification number assigned to all Finnish residents in 1971.

\section{Patient and public involvement statement}

Patients were not involved in the design or conduct of this study. There is no plan to disseminate the results to the participants.

\section{Physical heaviness of work and sitting at work}

Physical heaviness of work and sitting at work were assessed using participants' job titles, obtained from the national register of the Statistics Finland, and a validated gender-specific JEM. The matrix was developed using exposure information from a large nationally representative survey. ${ }^{30}$ The development of the two physical work characteristics (physical heaviness of work and sitting at work) was based on two distinct questions in the aforementioned survey: (1) 'Does your current job involve heavy physical work, in which you have to lift or carry heavy items, to dig, shovel or pound?' (yes/no) and (2) 'Do you in your current work need to sit (work machine or car driving not included) on an average at least five hours a day?' (yes/ no), respectively. ${ }^{30}$ The JEM includes the gender-specific information on the percentage $(0 \%-100 \%)$ of individuals within the occupation/occupational group reporting (1) physically heavy work and (2) prolonged sitting. For example, if $38 \%$ of women in a certain occupation reported having physically heavy work and $16 \%$ of women in the same occupation reported prolonged sitting, the likelihood of physical heaviness of work was set at 38 and the likelihood of sitting was set to 16 for all women within this occupation. The proportions of blue-collar (manual) workers were also determined based on the occupational titles for descriptive purposes. ${ }^{31}$

Participants' job titles in 1990 were originally coded according to the Classification of Occupations 1980 and were converted to Classification of Occupations 2001. ${ }^{32}$ Classification of Occupations 2001 is based on the fourdigit European International Standard Classification of Occupations 1988 (ISCO-88 (COM)). National circumstances are taken into account by adding five-digit occupational codes when necessary. The Classification of Occupations 2001 includes in total 445 codes and 270 of these appeared in the HBCS data.

Physical heaviness of work and sitting at work were categorised according to gender-specific quartiles. The quartiles of physical heaviness of work were $\leq 1.10,1.11-5.30$, $5.31-21.70$ and $\geq 21.71$ among women and $\leq 3.40$, 3.41$12.50,12.51-44.0$ and $\geq 44.01$ among men. The quartiles of sitting at work were $0,0.01-16.40,16.41-90.01$ and $\geq 90.01$ among women and $\leq 24.60,24.61-45.50$, $45.51-76.20$ and $\geq 76.21$ among men. 


\section{Mortality}

Dates and causes of death were obtained from the Finnish National Death Register. Survival time was calculated as the number of days between 1 January 1990 and death or the end of the follow-up, 31 December 2015, whichever occurred first. Cause of death was based on the primary cause of death in the register. International Classification of Diseases (ICD) codes for cardiovascular death included 400-499 in the ICD Ninth Revision and I00-I99 in the ICD 10th Revision, and for cancer death the codes 140-239 and C00-C97, respectively. External causes of death included codes (E)800-(E)999 in the ICD Ninth Revision and S00-Y84 in the 10th Revision. The rest of the causes of death were collapsed into a category 'Other causes'.

\section{Potential confounders}

Date of birth was retrieved from hospital birth records and was used to calculate subjects' age at the start of the follow-up. Years of education were derived from information on the level of education obtained from the Statistics Finland. Income per consumption unit was calculated as follows: household taxable income divided by the square root of the number of people in the household. ${ }^{33}$ Income was calculated as the average of years 1985, 1990 and 1995. These data were obtained from the Statistics Finland.

\section{Data analysis}

All analyses were run separately for men and women as genders differ markedly in both the exposures and outcome, that is, mortality. Background information is presented according to the quartiles of likelihood of physically heavy work. Linearity across quartiles was evaluated using the Cochran-Armitage test and analysis of variance with orthogonal polynomial contrasts. In the results, $\mathrm{p}$ for trend indicates the linearity test $\mathrm{p}$ value.

The relationship between likelihood of physically heavy work and prolonged sitting at work was assessed by using five-knot-restricted cubic spline regression. The length of the distribution of knots was located at the 5th, 27.5th, 50th, 72.5th and 95th percentiles. Survival estimator with attained age as the timescale was adjusted using inverse probability weights.

Cox regression models were used for analysing the relationships of physical heaviness of work and sitting at work with all-cause mortality. For analysing mortality from cardiovascular disease, cancer and external causes, competing risk regression was used. ${ }^{34}$ For each cause of death, the rest of the causes of death were considered as competing risks. The analyses were adjusted for age and years of education. All statistical analyses were carried out with Stata V.15.0 (StataCorp, College Station, TX).

\section{RESULTS}

The cohort was followed up for 237322 person-years. During the follow-up, 759 women and 1536 men died. Of the women, 175 died of cardiovascular disease, 363 of cancer, 52 of external cause, and 169 died of other causes. Of the men, 530 died of cardiovascular disease, 513 of cancer, 142 of external cause, and 351 died of other causes.

The characteristics of the study participants according to the quartiles of physical heaviness of work are given in table 1 . Those with higher likelihood of physically heavy

Table 1 Characteristics of men and women of the Helsinki Birth Cohort Study with an occupation in 1990

\begin{tabular}{|c|c|c|c|c|c|}
\hline & \multicolumn{4}{|c|}{ Quartiles of likelihood of physically heavy work } & \multirow[b]{2}{*}{ P value* } \\
\hline & $\mathbf{I}$ & II & III & IV & \\
\hline \multicolumn{6}{|l|}{ Women } \\
\hline $\mathrm{n}$ & 1312 & 1044 & 1115 & 1254 & \\
\hline Age, mean (SD) & $48.7(2.7)$ & $48.6(2.7)$ & $48.6(2.7)$ & $49.0(2.9)$ & 0.025 \\
\hline Education years, mean (SD) & $10.8(3.6)$ & $10.2(3.5)$ & $10.3(3.7)$ & $9.2(2.6)$ & $<0.001$ \\
\hline Blue-collar, n (\%) & $145(11)$ & $194(19)$ & $306(27)$ & $699(56)$ & $<0.001 \dagger$ \\
\hline Income, mean (SD)‡ & $42(18)$ & $41(19)$ & $39(20)$ & $35(21)$ & $<0.001$ \\
\hline Likelihood of prolonged sitting at work, median (IQR) & $90(8,90)$ & $90(45,96)$ & $0(0,28)$ & $4(0,16)$ & $<0.001$ \\
\hline \multicolumn{6}{|l|}{ Men } \\
\hline $\mathrm{n}$ & 1416 & 1110 & 1378 & 1306 & \\
\hline Age, mean (SD) & $48.7(2.6)$ & $48.8(2.7)$ & $48.7(2.7)$ & $48.6(2.8)$ & 0.70 \\
\hline Education years, mean (SD) & $13.2(3.8)$ & $11.7(3.9)$ & $10.1(3.0)$ & $8.6(2.2)$ & $<0.001$ \\
\hline Blue-collar, n (\%) & $212(15)$ & $324(29)$ & $773(56)$ & $1225(94)$ & $<0.001^{\dagger}$ \\
\hline Income, mean $(S D)^{\ddagger}$ & $48.6(20.5)$ & $45.5(22.5)$ & $36.2(15.3)$ & $31.8(12.0)$ & $<0.001$ \\
\hline Likelihood of prolonged sitting at work, median (IQR) & $90(77,97)$ & $52(44,73)$ & $43(26,46)$ & $11(1,44)$ & $<0.001$ \\
\hline
\end{tabular}

${ }^{*} \mathrm{P}$ for trend, Cochran-Armitage test.

†P of the $\chi^{2}$ test.

†Income per consumption unit=household income $/ \sqrt{ }$ (number of persons in the household). 
work had lower educational attainment and income, and lower likelihood of prolonged sitting at work than those with lower likelihood of physically heavy work. Further, among those with higher likelihood of physically heavy work, the proportion of blue-collar workers was higher.

The distributions of likelihoods of physically heavy work and prolonged sitting at work among men and women are shown in online supplementary figure 1 . The associations between physical heaviness of work and sitting at work are shown in online supplementary figure 2.

Higher likelihood of heavy physical work was associated with an increased risk of all-cause mortality among men both in the crude and adjusted models (adjusted for age and education) (table 2). Among women, higher likelihood of heavy physical work was associated with an increased risk of all-cause mortality only in the crude model but not when adjusted for age and years of education. Prolonged sitting at work was associated with a lower risk of all-cause mortality among men in both crude and adjusted models, while among women, prolonged sitting at work was associated with a lower risk of all-cause mortality only in the crude model but not when adjusted for age and years of education (table 2). See online supplementary figure 3 (physical heaviness of work) and online supplementary figure 4 (sitting at work), which show survival with attained age as the timescale for the lowest and highest quartiles of likelihood of the exposures.

Among men, higher likelihood of physically heavy work was associated with increased risks of cardiovascular death and death from external causes but not with that of cancer death (figure 1). Among women, no associations were found between physical heaviness of work and cause-specific mortality. Among men, prolonged sitting at work was associated with reduced risks of cardiovascular death and death from external causes (figure 2). Among women, prolonged sitting at work was not associated with cause-specific mortality.

\section{DISCUSSION}

Our findings suggest that men exposed to heavy physical work at their late career have an increased risk of mortality as compared with men in physically light occupations. Further, men in occupations with prolonged sitting had a lower risk of all-cause mortality than men in occupations with low level of sitting. Among women, neither physical heaviness of work nor sitting at work was associated with mortality. Increased mortality in men with high likelihood of exposure to physically heavy work and low likelihood of sitting was attributable to higher risk for death from cardiovascular diseases and external causes.

In contrast to our results, Autenrieth $e t a l^{11}$ reported a lower risk of all-cause and cardiovascular mortality among those with moderate occupational physical activity compared with those with light occupational physical activity level while Andersen $e t a l^{10}$ found lower all-cause mortality risk in women with heavy manual work compared with women at sitting type of work but no associations in men. Further, a meta-analysis of studies reporting risk ratios found an association between higher occupational physical activity and lower mortality in women. ${ }^{9}$ However, several studies have reported opposite results. ${ }^{5-8} 2535$ In line with our results, industry worker men with high physical job demands had a higher risk for all-cause and ischaemic heart disease mortality than men with low job demands in a 30 -year follow-up. ${ }^{35}$ In the classic Framingham Study, men with physically demanding job had a higher risk of cardiovascular death over a 24-year follow-up. ${ }^{5}$ Also other studies have suggested that physical demands at work increase mortality among men ${ }^{7}$ and in men and women combined. ${ }^{6825}$ Nevertheless, some studies have found no associations between physical job demands and mortality. ${ }^{12-14}$

There is a number of studies also on the association between sitting at work and mortality. Most of them have not observed any associations between sitting at work and mortality. ${ }^{16-20}$ However, Stamatakis et al reported higher all-cause and cancer mortality in women who mostly sat at work than in women who mostly stood or walked but no associations were found in men. ${ }^{3}$ Khaw et al reported a U-shaped association between physical activity at work and mortality, that is, those with sitting type of work and those with heavy manual job had higher mortality than those who mostly stand or do light physical work. ${ }^{4}$

The variability in the results of the previous studies may also partly derive from different operationalisations of exposure to physically heavy work. Some of the studies have assessed the intensity of occupational physical activity, classifying it into a few categories, ${ }^{4} 5111324$ whereas others have used individual physical or biomechanical exposures ${ }^{825}$ that require use of force or may have adverse effect on the locomotive system but do not necessarily lead to high overall energy expenditure, for example, awkward positions or repetitive hand movements. Our definition of physically heavy work included lifting, digging or carrying, which means that it captured occupations with the heaviest work tasks, which may be especially harmful for health.

It is possible that the age and gender of the target population influence the association between physical job demands and mortality. Our sample included men and women who were at their late career at baseline, between 45 and 57 years, whereas in many studies the samples have included the whole range of working age. ${ }^{6} 101113$ Plausibly, as physical capacity declines with age, physically strenuous tasks become more harmful for the worker ${ }^{36}$ and hence, the association between physical job demands and mortality is not as clear among young workers as among late-career workers. It is also possible that our findings reflect the influence of long-term exposure to physically heavy work and sitting. The participants are likely to have been working for decades, and it has been typical of this generation that the individuals have worked long time in the same or similar occupations. ${ }^{37} 38$ In the present study, physical heaviness of work and sitting at 


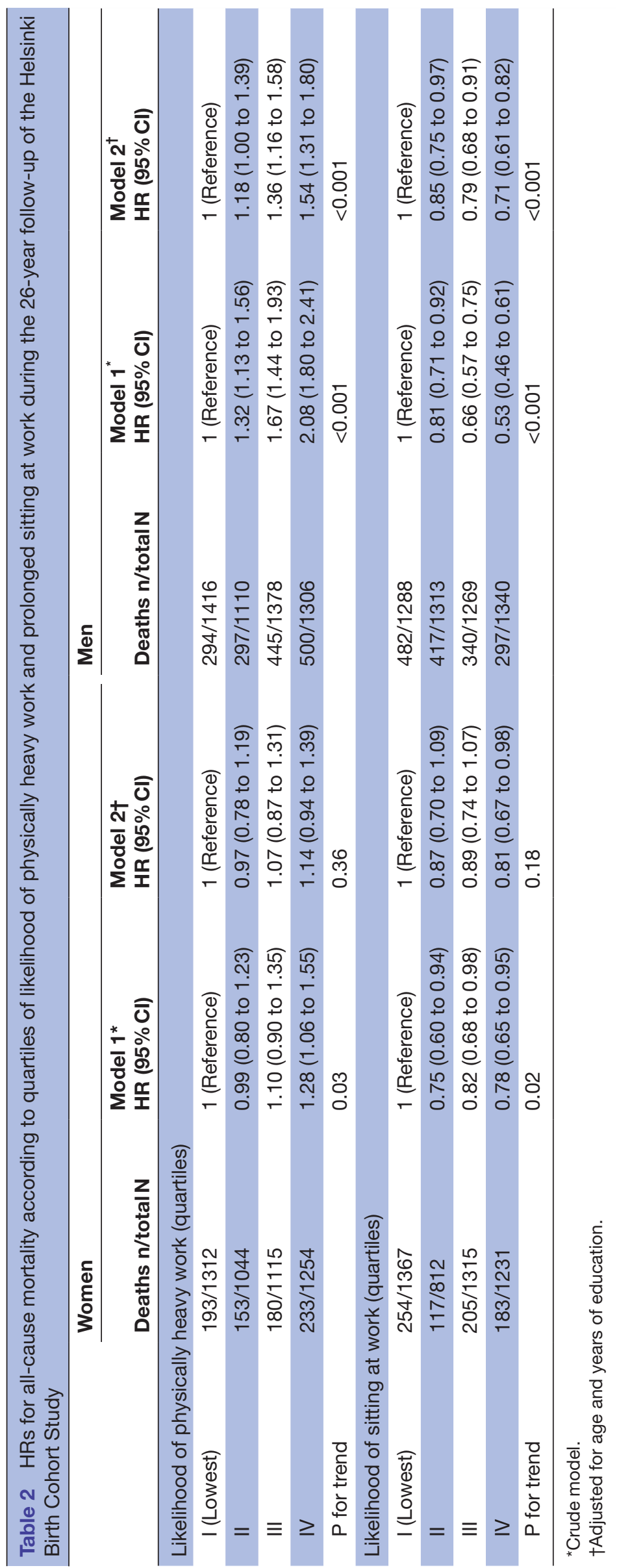

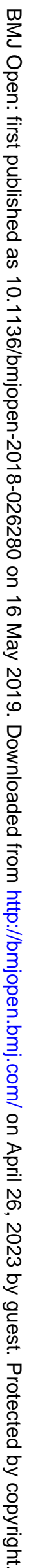


CVD

I $\begin{array}{r}\text { II } \\ \text { III } \\ \text { IV }\end{array}$

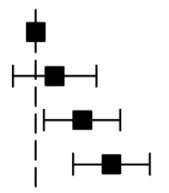

$p=0.16$

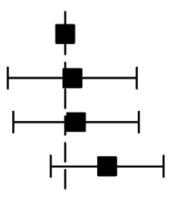

Cancer

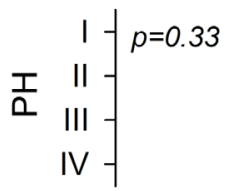

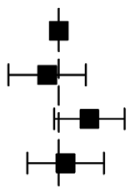

$p=0.60$

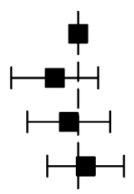

External causes
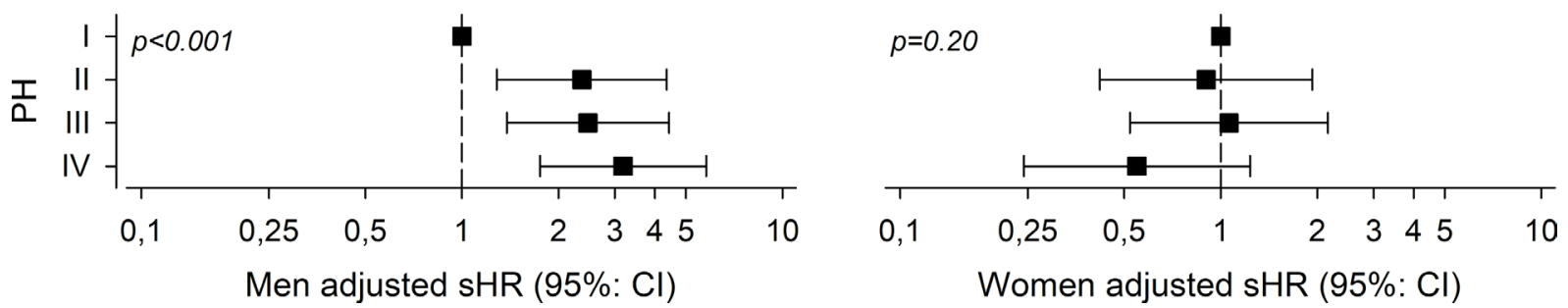

Figure 1 Adjusted sub-HRs (sHR) for cause-specific mortality (adjusted for age and years of education) according to the quartiles of likelihood of exposure to heavy physical work among men and women. I is the lowest and IV the highest quartile of physical heaviness $(\mathrm{PH})$ of work. $\mathrm{P}$ is the $\mathrm{p}$ value for trend. CVD, cardiovascular disease.

work were associated with mortality in men only. Men have higher mortality than women in general ${ }^{39}$ and physically heavy work may amplify the influence of other risk factors present in men. It is also likely that the content of work as a whole differs between men and women. ${ }^{40}$ In the present study, the distributions and the association between physical heaviness and sitting appeared to be different among men and women, as illustrated in
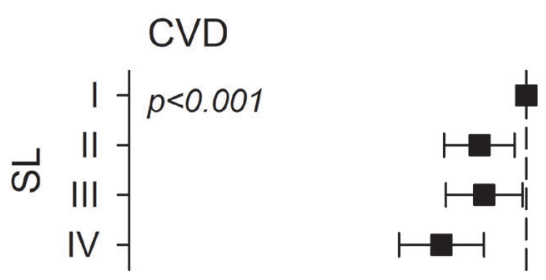

Cancer

$\vec{\omega} \begin{array}{r}\mathrm{II} \\ \mathrm{II} \\ \mathrm{IV}-f^{\prime}\end{array}$

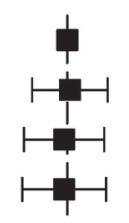

\section{External causes}

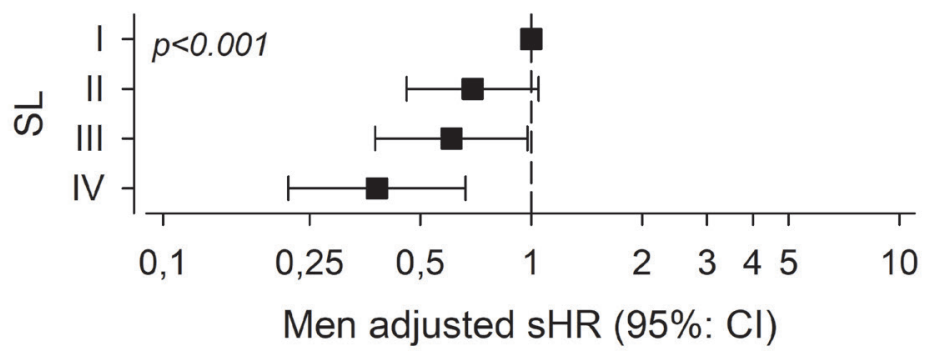

$p=0.33$

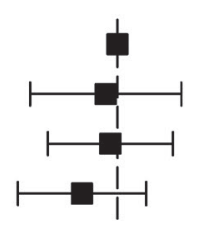

$p=0.24$
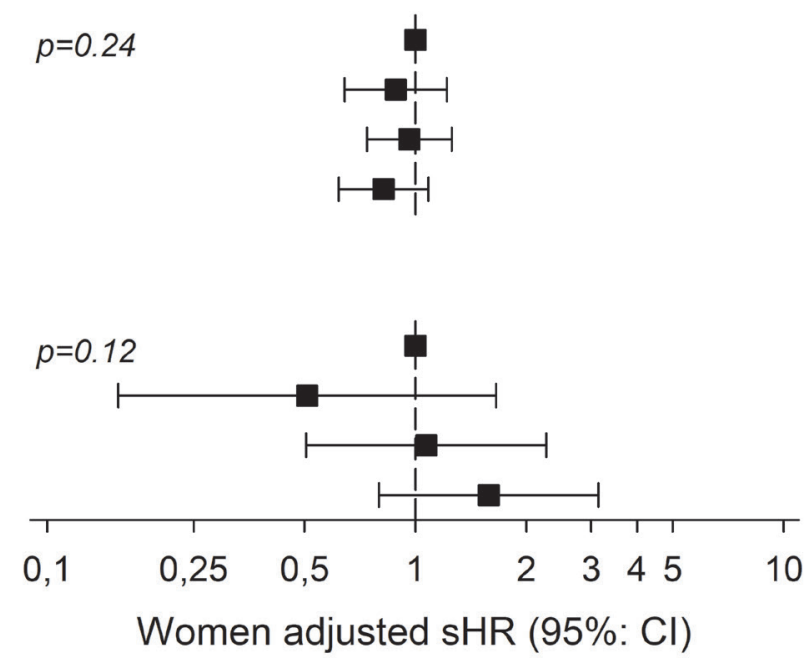

Figure 2 Adjusted sub-HRs (sHR) for cause-specific mortality (adjusted for age and years of education) according to the quartiles of likelihood of exposure to prolonged sitting at work among men and women. I is the lowest and IV the highest quartile of sitting level (SL) of work. $\mathrm{P}$ is the $\mathrm{p}$ value for trend. CVD, cardiovascular disease. 
the figures. On average, men had higher likelihood of exposure to physically heavy work than women, which may strengthen the association among men. It is also likely that the heaviest work tasks, which are the most harmful, are performed by men. ${ }^{40}$ However, studies are not consistent with regard to gender. Several studies that have studied only men have reported a higher mortality risk in men with high physical demands ${ }^{5735}$ whereas some studies have reported a lower risk in women at physically demanding work but no associations among men. ${ }^{910}$ The finding that no associations were found among women may at least partly be due to later manifestation of cardiovascular disease among women. In Europe, twice as many men than women die from cardiovascular disease before the age of 75 although the total number of cardiovascular deaths per year is similar between the sexes. ${ }^{41}$

The strongest candidates for the mediator of the effect of physical heaviness of work on mortality are cardiovascular diseases. This is supported by our analysis and others' ${ }^{35}$ analyses showing positive associations between physical demands and cardiovascular mortality. However, some studies reported a negative association ${ }^{11}$ or no association at all. ${ }^{514}$ But statistical power is likely to have been compromised, especially in the analyses with cause-specific mortality as the outcome. Some studies have also suggested an association between physically demanding work and higher cardiovascular morbidity. ${ }^{42}$ At the physiological level, the deleterious influence of physical job demands can be explained by haemodynamics. Physical demands increase the heart rate and the relative time that heart stays in systolic phase. ${ }^{21}$ Although relatively short bouts of physical activity, typical in leisure-time physical activity, are beneficial for the circulatory system, a physically demanding job means being several hours per day in a state of high heart rate and in relatively longer systole. ${ }^{22}{ }^{43}$ Longer systole reduces blood flow in the myocardium and induces stress against the arterial walls. ${ }^{21}{ }^{22}$ This may lead to inflammatory changes in the arteries and eventually contribute to the development of atherosclerosis. In terms of exercise physiology, the duration of occupational physical activity is often too long, its intensity too low and is accompanied with inadequate rest periods to produce beneficial training effects on cardiorespiratory fitness and consequently on cardiovascular health. $^{22}$

Studies investigating the associations between job exposures and mortality are prone to healthy worker selection bias. Only few prior studies have taken into account that workers with poorer health are more likely to move to physically lighter occupations during their work career. ${ }^{24}$ Hence, it is likely that many studies underestimate the risks of physical demands on health and exaggerate the risks of physically lighter jobs. ${ }^{24}$ When interpreting the results it should also be recalled that different job exposures are correlated. Hence, it is likely that physical heaviness of work and sitting at work reflect the effect of a larger set of risk or protective factors, which are correlated with other occupational exposures. Occupations requiring prolonged sitting rarely include chemical risk factors. It has been found that exposures tend to accumulate in certain occupational classes. ${ }^{44}$ Hence, the field of the target population may influence the results. The results may also partly be explained by differences in the lifestyles between workers with different occupational physical demands. Non-manual workers have physically lighter work tasks and they have been found to have better health habits than manual workers. ${ }^{45}$

The strengths of this study include a long follow-up, 26 years, until older age. Long follow-up may be crucial when studying mortality due to occupational physical demands in relation to NCDs like cardiovascular disease and cancer since it may take decades for them to develop. We were able to study both men and women. The data were obtained from high-quality national registers. In addition to all-cause mortality, we were able to analyse different causes of death as outcomes. We also took into account socioeconomic position using duration of education, which is important considering the strong influence of socioeconomic position on health and mortality. ${ }^{46}$ A limitation in using solely register data is that lifestyle factors, including leisure-time physical activity, could not be controlled for. Although we adjusted for socioeconomic position, there may still be residual confounding due to socioeconomic position. The sample included those who were working in 1990 when the participants' ages were between 45 and 57 . Hence, the sample is likely to have been affected by healthy worker selection, that is, the healthier individuals are more likely to have stayed at work while those with poorer health are more likely to become excluded from employment during their earlier work career. Therefore, the results cannot be generalised to younger workers. However, the sample is likely to be representative of Finnish working population aged 45 and older. Use of group-based estimates for the exposures, that is, JEM, may lead to non-differential misclassification errors as individual variation within occupations is omitted. This is likely to dilute true associations and hence, we consider our estimates to be conservative. ${ }^{30}$

In conclusion, men exposed to physically heavy work at their late career are at higher risk of death than those in physically light work. Men in strenuous occupations are susceptible for death from cardiovascular diseases and external causes. Among women, no such risks were found. These results underline the role of physical strain at work as a health risk among men at their late career. Preventive measures against cardiovascular diseases are warranted among late-career men in physically demanding jobs.

\section{Author affiliations}

${ }^{1}$ Folkhälsan Research Center, Helsinki, Finland

${ }^{2}$ Gerontology Research Centre, Faculty of Sport and Health Sciences, University of Jyvaskyla, Jyvaskyla, Finland

${ }^{3}$ Public Health Solutions, National Institute for Health and Welfare, Helsinki, Finland

${ }^{4}$ Primary Health Care Unit, Kuopio University Hospital, Kuopio, Finland

${ }^{5}$ Center for Life Course Health Research, University of Oulu, Oulu, Finland

${ }^{6}$ Finnish Institute of Occupational Health, Helsinki, Finland 
${ }^{7}$ Department of General Practice and Primary Health Care, University of Helsinki, Helsinki, Finland

Acknowledgements The results and findings of this study have earlier been published as an abstract (Mikkola TM et al. Occupational physical heaviness and sitting as predictors of mortality: a 26-year follow-up. Eur J Public Health 28(suppl_4): 80-81.D0I: 10.1093/eurpub/cky212.229).

Contributors TMM participated in the design of the study, analysis and interpretation of the data and drafted the manuscript. MBvB participated in the conception and design of the study, interpretation of the data and revised the draft critically for important intellectual content. MKS, LAM, SS and EVJ participated in the interpretation of data and revised the draft critically for important intellectual content. SS and EVJ provided also the job exposure matrix used in the study. HK analysed the data, participated in the interpretation of the results and revised the draft critically for important intellectual content. JE participated in the conception and design of the study, collection of data, interpretation of data and revised the draft critically for important intellectual content.

Funding This work was supported by Etera Mutual Pension Insurance Company; Emil Aaltonen Foundation; Finnish Foundation for Diabetes Research; Foundation for Pediatric Research, Novo Nordisk Foundation; Signe and Ane Gyllenberg Foundation; Sigrid Jusélius Foundation; Samfundet Folkhälsan; Finska Läkaresällskapet; Liv och Hälsa; European Commission within the 7th Framework Programme (DORIAN, grant agreement number 278603); and European Union Horizon 2020 programme (DYNAHEALTH grant number 633595; LifeCycle number 733206). The Academy of Finland supported MBvB (grant number 257239) and JGE (grant numbers 129369, 129907, 135072, 129255 and 126775).

Competing interests None declared.

Patient consent for publication None.

Ethics approval The study was approved by the Ethics Committee of Epidemiology and Public Health of the Hospital District of Helsinki and Uusimaa and that of the National Public Health Institute, Helsinki.

Provenance and peer review Not commissioned; externally peer reviewed.

Data sharing statement The data that support the findings of this study are available from Statistics Finland but restrictions apply to the availability of these data, which were used under licence for the current study, and so are not publicly available. Data are however available from the authors upon reasonable request and with permission of Statistics Finland.

Open access This is an open access article distributed in accordance with the Creative Commons Attribution Non Commercial (CC BY-NC 4.0) license, which permits others to distribute, remix, adapt, build upon this work non-commercially, and license their derivative works on different terms, provided the original work is properly cited, appropriate credit is given, any changes made indicated, and the use is non-commercial. See: http://creativecommons.org/licenses/by-nc/4.0/.

\section{REFERENCES}

1. Patel AV, Bernstein L, Deka A, et al. Leisure time spent sitting in relation to total mortality in a prospective cohort of US adults. Am J Epidemiol 2010;172:419-29.

2. Grøntved A, Hu FB. Television viewing and risk of type 2 diabetes, cardiovascular disease, and all-cause mortality: a meta-analysis. JAMA 2011;305:2448-55.

3. Stamatakis E, Chau JY, Pedisic Z, et al. Are sitting occupations associated with increased all-cause, cancer, and cardiovascular disease mortality risk? A pooled analysis of seven British population cohorts. PLoS One 2013;8:e73753.

4. Khaw KT, Jakes R, Bingham S, et al. Work and leisure time physical activity assessed using a simple, pragmatic, validated questionnaire and incident cardiovascular disease and all-cause mortality in men and women: The European Prospective Investigation into Cancer in Norfolk prospective population study. Int J Epidemiol 2006;35:1034-43.

5. Kannel WB, Belanger A, D'Agostino R, et al. Physical activity and physical demand on the job and risk of cardiovascular disease and death: the Framingham Study. Am Heart J 1986;112:820-5.

6. Holtermann A, Burr H, Hansen JV, et al. Occupational physical activity and mortality among Danish workers. Int Arch Occup Environ Health 2012;85:305-10.

7. Kristal-Boneh E, Harari G, Melamed S, et al. Association of physical activity at work with mortality in Israeli industrial employees: the CORDIS study. J Occup Environ Med 2000;42:127-35.
8. Bourgkard E, Wild P, Massin N, et al. Association of physical job demands, smoking and alcohol abuse with subsequent premature mortality: a 9-year follow-up population-based study. J Occup Health 2008;50:31-40.

9. Samitz G, Egger M, Zwahlen M. Domains of physical activity and allcause mortality: systematic review and dose-response meta-analysis of cohort studies. Int J Epidemiol 2011;40:1382-400.

10. Andersen LB, Schnohr P, Schroll M, et al. All-cause mortality associated with physical activity during leisure time, work, sports, and cycling to work. Arch Intern Med 2000;160:1621.

11. Autenrieth CS, Baumert J, Baumeister SE, et al. Association between domains of physical activity and all-cause, cardiovascular and cancer mortality. Eur J Epidemiol 2011;26:91-9.

12. Amick BC, McDonough $\mathrm{P}$, Chang $\mathrm{H}$, et al. Relationship between allcause mortality and cumulative working life course psychosocial and physical exposures in the United States labor market from 1968 to 1992. Psychosom Med 2002;64:370-81.

13. Huerta JM, Chirlaque MD, Tormo MJ, et al. Work, household, and leisure-time physical activity and risk of mortality in the EPIC-Spain cohort. Prev Med 2016;85:106-12.

14. Besson H, Ekelund U, Brage S, et al. Relationship between subdomains of total physical activity and mortality. Med Sci Sports Exerc 2008;40:1909-15.

15. van Uffelen JG, Wong J, Chau JY, et al. Occupational sitting and health risks: a systematic review. Am J Prev Med 2010;39:379-88.

16. van der Ploeg HP, Møller SV, Hannerz H, et al. Temporal changes in occupational sitting time in the Danish workforce and associations with all-cause mortality: results from the Danish work environment cohort study. Int J Behav Nutr Phys Act 2015;12:71.

17. Pulsford RM, Stamatakis E, Britton AR, et al. Associations of sitting behaviours with all-cause mortality over a 16-year follow-up: the Whitehall II study. Int J Epidemiol 2015;44:1909-16.

18. Virtanen SV, Notkola V. Socioeconomic inequalities in cardiovascular mortality and the role of work: a register study of Finnish men. Int $J$ Epidemiol 2002;31:614-21.

19. Kikuchi $\mathrm{H}$, Inoue $\mathrm{S}$, Odagiri $\mathrm{Y}$, et al. Occupational sitting time and risk of all-cause mortality among Japanese workers. Scand $J$ Work Environ Health 2015;41:519-28.

20. Kim Y, Wilkens LR, Park SY, et al. Association between various sedentary behaviours and all-cause, cardiovascular disease and cancer mortality: the Multiethnic Cohort Study. Int J Epidemiol 2013;42:1040-56.

21. Krause N. Physical activity and cardiovascular mortalitydisentangling the roles of work, fitness, and leisure. Scand J Work Environ Health 2010;36:349-55.

22. Holtermann A, Krause N, van der Beek AJ, et al. The physical activity paradox: six reasons why occupational physical activity (OPA) does not confer the cardiovascular health benefits that leisure time physical activity does. $\mathrm{Br} J$ Sports Med 2018;52:149-50.

23. Korshøj M, Lidegaard M, Kittel F, et al. The relation of ambulatory heart rate with all-cause mortality among middle-aged men: a prospective cohort study. PLoS One 2015;10:e0121729.

24. Krause N, Arah OA, Kauhanen J. Physical activity and 22-year all-cause and coronary heart disease mortality. Am J Ind Med 2017;60:976-90.

25. Niedhammer I, Bourgkard E, Chau N. Lorhandicap Study Group. Occupational and behavioural factors in the explanation of social inequalities in premature and total mortality: a 12.5-year follow-up in the Lorhandicap study. Eur J Epidemiol 2011;26:1-12.

26. Wanner M, Tarnutzer S, Martin BW, et al. Impact of different domains of physical activity on cause-specific mortality: a longitudinal study. Prev Med 2014;62:89-95.

27. Dopart PJ, Friesen MC. New Opportunities in Exposure Assessment of Occupational Epidemiology: Use of Measurements to Aid Exposure Reconstruction in Population-Based Studies. Curr Environ Health Rep 2017;4:355-63.

28. Eriksson JG, Forsén T, Tuomilehto J, et al. Catch-up growth in childhood and death from coronary heart disease: longitudinal study. BMJ 1999:318:427-31.

29. Barker DJ, Osmond C, Forsén TJ, et al. Trajectories of growth among children who have coronary events as adults. N Engl J Med 2005;353:1802-9.

30. Solovieva S, Pehkonen I, Kausto J, et al. Development and validation of a job exposure matrix for physical risk factors in low back pain. PLoS One 2012;7:e48680-7.

31. Central Statistical Office of Finland. Classification of socioeconomic groups: Handbooks 17. Helsinki, Finland, 1989.

32. Statistics Finland. Classification of Occupations. 2001. http://www. stat.fi/meta/luokitukset/ammatti/001-2001/index en.html [Accessed 7 Dec 2017]. 
33. OECD. What are equivalence scales? 2011:1-2. http://www.oecd. org/eco/growth/OECD-Note-EquivalenceScales.pdf

34. Fine JP, Gray RJ. Proportional Hazards Model for the Subdistribution of a Competing Risk A Proportional Hazards Model for the Subdistribution of a Competing Risk. J Am Stat Assoc 1999;1459:37-41.

35. Holtermann A, Mortensen OS, Burr H, et al. Physical demands at work, physical fitness, and 30-year ischaemic heart disease and all-cause mortality in the Copenhagen Male Study. Scand J Work Environ Health 2010;36:357-65.

36. IImarinen J. Job design for the aged with regard to decline in their maximal aerobic capacity: Part I - Guidelines for the practitioner. Int $J$ Ind Ergon 1992;10:53-63.

37. Lyons ST, Schweitzer L, Ng ESW. How have careers changed? An investigation of changing career patterns across four generations. $J$ Manag Psychol 2015;30:8-21.

38. von Bonsdorff MB, Seitsamo J, von Bonsdorff ME, et al. Job strain among blue-collar and white-collar employees as a determinant of total mortality: a 28-year population-based follow-up. BMJ Open 2012;2:e000860.

39. Wang $\mathrm{H}$, Naghavi $\mathrm{M}$, Allen $\mathrm{C}$, et al. Global, regional, and national life expectancy, all-cause mortality, and cause-specific mortality for 249 causes of death, 1980-2015: a systematic analysis for the Global Burden of Disease Study 2015. Lancet 2016;388:1459-544.
40. Messing $\mathrm{K}$, Punnett $\mathrm{L}$, Bond $\mathrm{M}$, et al. Be the fairest of them all: challenges and recommendations for the treatment of gender in occupational health research. Am J Ind Med 2003;43:618-29.

41. Townsend N, Wilson L, Bhatnagar P, et al. Cardiovascular disease in Europe: epidemiological update 2016. Eur Heart $J$ 2016;37:3232-45.

42. Clays E, Casini A, Van Herck K, et al. Do psychosocial job resources buffer the relation between physical work demands and coronary heart disease? A prospective study among men. Int Arch Occup Environ Health 2016;89:1299-307.

43. Korshøj M, Clays E, Lidegaard M, et al. Is aerobic workload positively related to ambulatory blood pressure? A cross-sectional field study among cleaners. Eur J Appl Physiol 2016;116:145-52.

44. Borg V, Kristensen TS. Social class and self-rated health: can the gradient be explained by differences in life style or work environment? Soc Sci Med 2000;51:1019-30.

45. Clougherty JE, Souza K, Cullen MR. Work and its role in shaping the social gradient in health. Ann N Y Acad Sci 2010;1186:102-24.

46. Stringhini S, Carmeli $C$, Jokela $\mathrm{M}$, et al. Socioeconomic status and the $25 \times 25$ risk factors as determinants of premature mortality: a multicohort study and meta-analysis of 1.7 million men and women. Lancet 2017;389:1229-37. 